\title{
An Administrator's Perspective of Trends in Community Mental Health: An Interview With Norman J. Groetzinger
}

\author{
Edward Gumz \\ Loyola University Chicago, egumz@luc.edu
}

Follow this and additional works at: https://ecommons.luc.edu/socialwork_facpubs

Part of the Social Work Commons

\section{Recommended Citation}

An Administrator's Perspective of Trends in Community Mental Health: An Interview With Norman J. Groetzinger Edward J. Gumz Families in Society, 2004, v. 85, no. 3 DOI: 10.1606/1044-3894.1497

This Article is brought to you for free and open access by the Faculty Publications and Other Works by Department at Loyola eCommons. It has been accepted for inclusion in Social Work: School of Social Work Faculty Publications and Other Works by an authorized administrator of Loyola eCommons. For more information, please contact ecommons@luc.edu.

\section{c) (†) $\ominus$}

This work is licensed under a Creative Commons Attribution-Noncommercial-No Derivative Works 3.0 License.

(c) Alliance for Children and Families, 2009 


\title{
An Administrator's Perspective of Trends in Community Mental Health: An Interview With Norman J. Groetzinger
}

\author{
Edward J. Gumz
}

\begin{abstract}
In this interview, Norman J. Groetzinger discusses major trends and challenges in community mental health since 1975 when he became executive director of the Counseling Center of Lake View, in a Chicago neighborhood. He places these trends in broader state and federal contexts and illustrates how mental health agencies and the Counseling Center of Lake View, in particular, have responded to these challenges. Many times persons with mental illness were better served as a result, but at times the changes ended up complicating how professionals go about doing their work.
\end{abstract}

$\mathbf{N}$ orman J. Groetzinger, interviewed in 2004, is the executive director of the Counseling Center of Lake View, a community mental health agency in Chicago. Groetzinger, who holds three master's degrees-in social work (health policy and planning), theology, and East Asian studies - has been the executive director of the agency since its founding in 1975. The Lake View (or "Lakeview") community is located near Lake Michigan, 3 miles north of Chicago's center, the Loop. Once a multiethnic workingclass area plagued by disinvestment, it has evolved into a gentrified, predominantly Caucasian locality with a strong gay and lesbian presence. Lake View has been a mecca for homeless youth since the 1960s. The area is known for the transiency of its residents and has a zip code with among the highest property ownership turnover rates in the United States. Wrigley Field is in the community and anchors an entertainment district that is actively promoted by the City of Chicago for tourism.
EG: When you first became executive director of the Counseling Center of Lake View, what were some of the issues that you faced and how did you, the agency staff, board, etcetera, deal with these issues?

NG: Well, when I first became executive director, we're going back to 1975! So we have to think of this in two different contexts. First, the community-based mental health system was in its early stages of development. Second, in terms of this particular job and this particular agency, when I took the job, I had a staff of $2 \frac{1}{2}$ people. So we were very small, and we were also very grassroots. On top of that, I was a lame duck from the day I took the job, because it was supposed to be a 1-year job only. So, that's an element of a particular historical experience that you might find quite different from what other people have experienced.

In July 1975, we had two programs: what is now called the Latino Counseling Services and the Lake View Alcoholism Program. I was able to stay on the job a year later because we 
received a grant for child and adolescent services, and that gave my job some stability. In the early stages of the agency, the board was composed largely of social service paraprofessionals, many of whom were human service workers in Great Society programs of the City of Chicago. So there was not very much professional expertise on that board, and the board was also split into factions; but there was a strong personal investment in bringing mental health services "to the people". Each of the programs had an advisory board which fed into the overall agency board. So, a lot of what I was dealing with in the early years was factionalism and conflict between different entities within the agency; it was hard to even call it an agency. It was like an umbrella board overseeing the different programs while each had their own policies, procedures, and values. There were a lot of duplicate policies, so the biggest struggle in the early years was just to even begin to make it an agency with programs.

The other thing that I certainly think about when reflecting back on that period, is that okay, I was the executive director. I was also the chief financial officer; I did all the financial work. I didn't have a bookkeeper, let alone a controller. I was the human resources manager and I was the development officer. Because of the size I was even the backup receptionist, and I was the guy who, when there was a broken lock, fixed the lock! So basically I was very much a jack-of-all-trades. It was a wonderful learning experience, not something that in retrospect that I regret, because I think it gives me, as an executive director today, a sense of what these different people in these different positions ought to be doing and what their job is. I think that's extremely valuable. Being executive director in a small agency is, in fact, a wonderful way to start in that career. You get an idea of the many different dimensions of organizational operations.

So, one thing I really had to work on was developing a board. I knew I would need to rely on the board to bring a lot of the technical expertise that I didn't have. I was looking for board members with financial expertise, people who had expertise in human resources, and people with expertise in strategic planning. In fact, I still look for board members with an array of such talents because I think that's essential to the board's contribution. But today's board has less of a hands-on role in those kinds of arenas than they did for many years at the beginning. They now are more of an oversight entity. In the early years we actually sat down and worked things out in committees with the board members who had the expertise, so in that sense, it was a much more participatory board than it is at this point in history.

The other thing I think about is that financially, it was year-to-year; survival was the big issue, because we were young. There were other agencies that started at the same time, some of which survived and some of which are long gone. And our state funding was always problematic.

One of the biggest problems with that situation was staff development and staff retention. For financial reasons, in order to survive, any time any position came open in the agency, we had to hire at the entry level. We would train staff for the job, and then they'd leave for a government or hospital job or to an established private agency, where they would get a higher salary than we could offer. So, that was very frustrating. Of my three program managers in the early period, two of them were people right out of school. Basically, they had master's degrees, that's it. These individuals were the clinical directors of mental health and substance abuse programs. It took many years before, as an agency, we could require that a person hired at the supervisory level have 5 years or preferably 10 years experience.

We had a lot of difficulty finding competent support staff. We'd train them and then they'd go downtown and work for a bank and make twice as much. So, we had a lot of turnover and a lot of frustration.

EG: So over the years the agency has stabilized; it has grown. The board is a true board of directors, and the staff has become more professional. How has your role as executive director changed from those early years when you were jack-of-all-trades to the director you are today?

NG: Well, you know, we've been through so many changes over these last 3 decades, it's hard to mention all of them. I talked earlier on about how our basic concern really was survival. At some point, we were able to move from a survival mode into what I'll call a quality mode. So my concern was no longer just whether we could survive from year to year, but aspiring to an ever improving quality level of performance. I always felt that we were providing good services, because we have always had very committed staff, and that's been very gratifying. At the same time, over the years, as the whole community mental health system has grown and changed, the expectations of us have increased. This is not limited to expectations in terms of performance with clients; there has also been a plethora of new regulations. For example, labor law has become increasingly something we have to attend to; new regulations came into play from the state such as monitoring and overseeing fundraising activities. More recently, the state required that an agency such as ours be accredited. We chose for our accrediting body the one which, to be honest with you, I thought would be the most challenging-the Joint Commission on the Accreditation of Healthcare Organizations. Partly, the challenge comes from its origin as the accrediting agency for hospitals. In any case, it has required us to create more internal bureaucracy, because there's just so much more accountability for so many different functions, from policies and procedures manuals to posting safety procedures. Increasingly my role has become more one of oversight: working with the human resources manager, working with the controller, and working with the medical director. I now meet on a fairly regular basis with program managers, so that I know what they're doing; we do a lot of program planning. That's the key element in my mind, what's good about the agency-that we plan. We've done strategic plans every 3 to 4 years and an annual 
plan each year. We sit down with each of the departments, be it a program or an administrative department, and look at where those departments have been and where they need to be going in the future. So my role in that sense has become more one of planning, oversight, and coordination. And that's worked for us very well.

Another thing which I've been thinking about is simply the whole idea of community-based care. When we started, most of the funding from the state of Illinois for mental health was for hospital-based service. This tended to be run by psychiatrists. I remember conversations that we had with some of the individuals running those departments, who felt that outreach was the same as solicitation of customers, which at that point was against medical ethics. When somebody was released from the state-operated psychiatric institution into the community, the staff of such community programs might try to reach them by phone, but they would never send anybody out to actually look for the person. They didn't do aggressive outreach. They were really looking for a motivated therapy client. These programs were a very poor fit for many of our clients. Over a period of time, it is not just the Counseling Center of Lake View but many other community-based agencies which have come to do outreach; the staff work out in the community as much as they work in the office with clients. It has really become the norm and the best-practice model; it is understood that this is how you serve your more chronic populations. The acceptance of the community-based model is a very major change that has taken place over the years.

Also, we really have a much higher degree of acceptance of mental health services in general. We have to look at the whole issue of stigma. Stigma, of course, is a problem for a variety of reasons, but the biggest problem with stigma is that it deters people from seeking care and services they can benefit from. As stigma is reduced, more people request care. This new environment also means that when I'm out in the community and talk about being an executive director of the local community mental health agency, people don't snicker. That was very much the response I met when I started. In the early days, I'd just as soon not talk about my work, because I knew I was going to get some really kind of dismissive, demeaning, disrespectful type of response. I don't find that anymore. It's more like, "Oh, great. That's something we really need. I appreciate what you're doing." The work of the Alliance for the Mentally Ill, now the National Alliance for the Mentally Ill, and especially the family movement, has changed the whole environment in which we operate.

When you're an executive director, obviously, funding, funding, funding is a major concern. Back in the old days, in some ways, that was easier because we were funded mostly on grants from the state, and supplemented by the United Way, the city, and foundations. I knew how much money I was going to receive from the state. Through the year, I could control my expenses pretty well; we were always within 1 to $2 \%$ of projections. People would look at the agency and say, gee, how do you come so close to the estimates of what you're going to receive and expend? The grants came in and we knew how much we were getting from the grant; we knew our basic expenses, our personnel costs. The biggest problem I had I think was utilities, because you'd have a cold winter and gas bills would go up or a hot summer and the electric bill would go up. Nowadays it's much more complicated, of course. In Illinois we haven't been quite as exposed to the whole onslaught of managed care in the public sector as I think people have in most of the country. But nevertheless, as we moved into more third-party billing, I had to create a billing department. So that's been the story of community mental health. By the ' 90 s, we renamed mental health and substance abuse as behavioral healthcare.

I've heard some interesting critiques of that evolution. As a social service movement, we were very much grounded in a rehabilitation philosophy that is more of a wellness philosophy and more of a growth philosophy. When the mental health field became more medical, we got pushed into a deficit model, because you're looking at something that is amiss. There's something wrong with patients and you're supposed to "fix it". This can be very different from focusing on helping the people who come in for services to do better, focusing on their strengths. But there's been a reaction to that I think. More recently, we have seen the growth of the whole recovery movement which is now being promoted even by the federal government. That's looking again and saying, "Okay there are folks who have mental illness, but the basic need here is for them to be able to function in society just like somebody with heart disease or diabetes would be hoping to function and live a quality life" - which kind of really is Social Work 101.... I've had a lot of thoughts about changes in care and treatment. I picked up on five or six trends that I think have been significant.

One that has been especially important to me is culturally-sensitive care. That goes back to the fact that I personally have a master's degree in East Asian studies. I spent more than 2 years studying one entirely different culture, and following that two more years as a Peace Corps volunteer in India. So I've had the experience of being an individual living in a different cultural milieu. I observed my fellow Peace Corps volunteers, and it was very clear to me that if any of us as Peace Corps volunteers were to experience any kind of personal problems, we would not have gone to an Indian for help; we would have gone to another American. And so, just translating that to what it must be like for the recent immigrant, be they from Vietnam or Laos or Guatemala or Costa Rica or Russia or wherever: it's important that there be someone to talk to, who you feel has some understanding of where you're coming from. I'm a strong believer in culturally-sensitive care; that is, from a consumer's perspective. Partly this reflects an increasing sophistication within the field, but it's also partly the changing demographics of the United States. More and more people who live here are people who are recent immigrants, and so there's more and more emphasis on cultural competence 
and cultural sensitivity. In our particular neighborhood, part of that has been the presence of the gay and lesbian population. That's always been part of the culture in this agency. We had a close brother-sister relationship with an emerging gay and lesbian social services agency, sharing space for a number of years. So we have a lot of experience working with the community. Many of our staff here have been gay or lesbian. In addition, responding to a Spanishspeaking segment in our community, we have always hired bilingual-bicultural receptionist staff.

Another change in terms of how we work with clients is home-based care. I pointed out earlier that the agency started out with a clinic model of care, with people coming in. The shift came early and was expressed in our first mission statement: "Serving the underserved, reaching the hard to reach." This agency has emphasized home-based care and care out in the community where people are, rather than having an expectation that people be willing or able to come in. In addition, we have understood that home-based mental health care must be integrated with many other aspects of the patient's social situation; for example, ensuring that people have access to income, entitlements, and other services and resources. They have to have access to food; they need access to shelter; and they must have access to medical care. So in terms of the way this agency, but not just this agency, the field, has understood the way you provide services to the person with long-term mental illness, it is a matter of serving people out in the community, not just in the agency. We think that's embedded in the active community treatment model, which is now considered an "evidence-based" practice model.

Going back to 1975 in the state of Illinois, there was an alcoholism division in the Department of Mental Health. There was a separate agency that dealt with substance abuse. Those two entities were combined at some point, and then, that split off from mental health. So there was a huge hiatus between mental health services and substance abuse services. The workers would not communicate; the workers did not have good opinions of each other, and the result of that was that many clients did not get the kind of care they should receive. Over a period of time, not only has consciousness changed, but the clientele of those we see in the public type of agencies has changed. So we now understand that when you see people who bring both mental health and substance abuse issues, that's more of the typical client than the exception. We still have problems at the state level, in getting the state officials to recognize that. It's ridiculous to maintain this artificial segregation between mental health and substance abuse services. So I think it's increasingly accepted in the field that we need to develop integrated treatment. That, of course, has many implications for staff training and development. We're beyond simply cross training; it's really integrated training that we need to be moving toward.

Housing is also a crucial issue for persons with mental illness. In the state of Illinois, we have done very poorly when it comes to housing persons with mental illness.
We've created some supportive housing but not nearly enough. The need and our ability to provide services using case management and up to 24-hour staff supervision for people living in their own apartments-or maybe four people or eight people living in some kind of congregate facility — is widely recognized.

So I think that these are arenas that definitely have changed in terms of our understanding of the needs of the population. There has also been an evolution in who the population is, because 30 years ago, we were still dealing with the de-institutionalized patient as someone who had spent a long period of time in a psychiatric institution and who was being moved from that institution out into the socalled community. Too often, that "community" was another institution such as a nursing home.

Nowadays, people aren't having that experience of years and years in psychiatric institutions, with very rare exceptions. They may never have been in an institution, because there are less of them, many fewer beds. It's harder to get into them because of civil rights legislation, or if they have been, they've been in for short periods of time. Perhaps the stay is going to be 2 weeks; often less. So the clientele is a clientele that's been in the community and has not been in those large institutions where people were basically pacified and infantilized; these are people who have had to survive in the community and on the street. And that I think had huge ramifications. These are difficulties that come along with working with the mentally ill substance abuser. So again, we need a more skilled staff. We need case managers who can work with these folks with complicated symptoms and life circumstances.

EG: We've seen how economic forces have shaped the work of the agency; now I'd like to turn a bit to the politicalpolitical influences on the national, state, and local levels. How have those influences shaped what has happened at the Counseling Center of Lake View and what the agency has been able to do or not to do?

NG: Well, I talked a little bit about the local level, both in terms of my community involvement and also in terms of the general stigma issue. The local level has never been particularly important in terms of funding. But again, just to reiterate, the Counseling Center of Lake View is, I think, now understood and perceived to be an important community service institution. So the local political support is here. I can go around the community and talk about what I do and have a reasonable conversation and really have some very good conversations with people in the neighborhood on mental health, their experiences with substance abuse and mental illness in their own families. People are very open and forthcoming with me about that kind of stuff. So to that degree, local support is really there. Working with the merchants has been very helpful to the agency. When we wanted to purchase the building, we were not faced with a "not-in-my-back yard" type of phenomenon; they actually contributed to our capital campaign. 
At the state level, there is the politics of it and the economics of it. The state legislature has become increasingly supportive of community mental health services in particular. I can't quite say the same for the substance abuse side of the equation. Mental health is now seen not so much as a personality fault. Clearly, supporting mental health services is bipartisan; our supporters in Springfield are as likely to be Republicans as Democrats. Everybody understands that mental health goes across party lines, that Republicans can have nervous breakdowns as easily as Democrats, can become clinically depressed, or whatever. So the support has increased. Agency directors and advocacy groups throughout the state are doing a good job of talking to their local legislators and this has really made a world of difference.

At the administrative level of the state, they still tend to be very preoccupied with maintaining the state-operated institutions, despite the fact that there are less of them, and that the number of beds is less. Those institutions no longer take up the majority of the state's budget, but all things considered, a disproportionate share of the state's budget. So, it continues to be disappointing, I think, for those of us in the community that the state bureaucracy is focused on its own institutions, and does not have sufficient understanding of the fact that people live in their own communities. That's where they live. They go into the hospital because they're sick, and then they're back into the community. The community system is the core. The hospitals are there for backup care. They see it the other way around: the hospitals are there, the community is what you release people to. And so they've just got an inverse understanding of reality. That has not moved forward.

The other thing that has not moved forward is the state's preoccupation with the seriously mentally ill adults and the seriously emotionally disturbed kids, so that they do not want their money spent on large numbers of people who need or want mental health care but don't fit into the kind of target populations that are defined by certain DSM diagnoses. A larger and larger percentage of our population is uninsured, and when it comes to mental health, people are even more underinsured than in other ways. There are a huge number of people in our communities who would access services if there were not the financial barriers. The state is the major funder, so if the state is not funding services, the money isn't going to be there for them.

At the federal level, it's been kind of a back-and-forth proposition. During the Kennedy and Johnson era, the Comprehensive Community Mental Health Center Act was passed in 1963. The vision was that the entire United States would be blanketed by comprehensive community mental health centers, providing services to anyone who needed those services. That vision became dimmer over time. During the Carter era, the Congress passed the Mental Health Systems Act, which would have focused more money on children's services, services for the elderly, services for minority populations, and services for persons with serious mental illness.
After Reagan was elected, he block-granted funding to the states, and the focus on the child, the focus on the elderly, and the focus on people of color all got lost. He did maintain a focus on persons with serious mental illness; that fit very nicely with, as in Illinois, the state's focus on that population. Recently I think, there has been a little bit more leadership coming out of Washington with some interest in children, the elderly, cultural groups, ethnic groups, and so forth. So I think the federal government at one point in history created an image or vision for what things ought to be like, but that vision has never been the one that's prevailed.

The other thing I think that's been important politically is the Alliance for the Mentally Ill, which is now called the National Alliance for the Mentally Ill. For a number of years, NAMI really was focused on brain research; that fit really well with the Reagan era agenda. The Reaganites didn't want research done on social variables such as the relationship between poverty and mental illness and the brain research did move forward. We've definitely had the impact of new generations of medications. In recent years, NAMI has really pursued the agenda around social issues. For example, they had an important role in Washington, DC, lobbying and educating the Congress on issues of homelessness and more recently, they've shown definite leadership on the issue of the incarceration of persons with mental illness. The figures are quite devastating when you look at the number of people who are in our jails, and in prison at the state level, while not quite so much at the federal level. The youth who are in our juvenile detention centers, they are children, kids with emotional problems. We have a huge reduction in the state operated psychiatric institutions but we have a huge increase in the number of people in jails, prisons, and juvenile detention centers.

Now some people want to make a direct relationship between these two phenomena, which I think is a mistake. What is often left out of the equation I think are two aspects of it. Certainly we have more community services than we had when de-institutionalization started in the 1950s. And we have community services that are capable of providing services for the seriously mentally ill. Where we have a huge gap is in housing. Because of the crisis in housing affordability, the loss of SROs-single room occupancy type of housing-people are now on the street who weren't on the street in let's say the '70s. The deinstitutionalization process began in the ' 50 s, and it was largely complete by the late '70s. It wasn't until the early ' 80 s that we started to see this phenomenon of the homeless mentally ill. In my mind, I think that was much more related or equally related to the cutbacks in federal housing programs that began in the '80s. At the same time, the housing market has become more and more distorted; without a subsidy of some sort, it's virtually impossible to build affordable housing.

We've also had some decline in the value of public income support. In Illinois we had the elimination of General Assistance. General Assistance, a state-funded program, at 
one time provided $\$ 199$ per month to a single, unemployed male. These men would take their $\$ 199$ and rent their SRO room for a month, go to the pantries for food, hawk newspapers, whatever. They survived. They weren't living on the street. Sooner or later, persons with mental illness are going to end up in jail because even if they're going to do something that might not be particularly illegal ... they sometimes become a bit of a public nuisance. Or maybe they're going to do something that is maybe more of a function of their illness that gets them arrested, or in some cases, we've even had reports of police departments having a policy of picking people up and putting them in jail for protective reasons. They can't put them in the mental hospital, because they don't necessarily fit the criteria for involuntary commitment, but the police officer who sees somebody who is about to freeze to death may feel that that person is better off in jail than on the street. So we haven't had enough growth in housing for the community approach to mental health.

Over the years, the family movement has come to provide a constituency that did not previously exist. Historically, especially when improper parenting was seen as the genesis of mental illness, parents of the mentally ill were stigmatized. So they certainly didn't go down to Springfield to advocate for their children. Now they are organized. I think it is an incredibly important social phenomenon, a social transformation.

So to my mind those are some of the key political things that I see over the years.

EG: You touched earlier on the kind of staff that the agency needs in response to changes in mental health treatment, changes in types of mental health sciences. Could you say more about that?

NG: Yes, I think I started to talk about this, I think I started to talk about the case manager.

EG: The case manager who needs to be clinically competent. NG: More clinically competent, definitely. For many years we were hiring college graduates, some of whom might have a BSW or BA in psychology. Others have had degrees in sociology, art, whatever. We were able to train them in a relatively short period of time to do the functions-the supportive functions - that case managers performed. Over the years the job became more difficult. We rarely hire a person right out of college, perhaps a bachelors in social work, yes. But some of those other majors-I doubt it. We have started to hire persons with an MA in case management, or persons with several years of prior experience. And certainly they need to be able to address the substance abuse issue; so there is a lot more staff training and development required, and we look for more experienced people.

Interestingly enough, psychiatry has again become more important. I think this has to do with some of the new medications or perhaps it's just a matter of the kind of jockeying that takes place between professions. Psychiatry has had a bit of a revival. I would say that psychiatrists, for the most part, no longer do therapy. They're basically oriented around medications. Hopefully, you can find psychiatrists who are trained in community psychiatry, and therefore they understand not only how to work with clients around meds, but also how to work with the other staff, because for the psychiatrists to be successful in what they do, they need to be able to listen to the case manager who sees the individuals out in the community and knows what their lives are really like, who knows what they really act like when they're not in the office. So, the community psychiatrist who has the knowledge base on the psychotropic meds and can also communicate well with the case managers, with the counselor or therapist, can do a bang-up job. So I personally have more appreciation for psychiatry as it provides an integrative and leadership role in the agency.

Since we became more third-party funded, and since we had to be more behavioral in the way we understood things, it doesn't necessarily mean that therapy has to be more behavioral. People still can do therapy in a variety of different ways, but they have to be able to understand it in terms of behaviors. They have to be able to look at outcomes in terms of behaviors, so again, I don't think it's necessarily that people have to use techniques which are more behavioral, but they have to be able to conceptualize what they're doing, and they have to recognize what people are being referred for. Clients themselves have a behavioral understanding of what they want out of treatment. Therapists have to be able to address that and that fits very much into the demand for charting, because the nature of third-party billing is that charting becomes extremely important in terms of having a treatment plan which clarifies: here's the problem; here are the objectives; here are the goals; here's the time line and the expected outcomes. It is a very systematic kind of approach, and there is the requirement of writing it down systematically. Then on top of that, there's the additional burden when the charting isn't done properly, when there is a missing signature, when we're providing a service that wasn't in the treatment plan. Then the auditors come in, and there will be a payback. Not that you didn't deliver the service, but the service wasn't in the treatment plan; therefore, you have to pay back. Or, you know, this treatment plan was supposed to be signed by the client, the primary clinician, and maybe a couple other folks. A signature is missing. You have to pay back the money. So, I think that changes the nature of the work for the clinician quite significantly from the way it would have been at one point in history. Currently, the clinician must devote more attention to specific documentation requirements. So those are some of the things that strike me as important when it comes to the nature of the staff that we need to have here.

EG: How did you become executive director of the Counseling Center of Lake View? 
NG: It's somewhat of a unique story. The predecessor to the Counseling Center of Lake View, called the Lake View Mental Health Council, was formed in 1969 and was incorporated in 1972. I had done some volunteer work with the group and had been a board member. I had spent a whole summer working on a federal grant proposal to develop mental health services for children. During that period of time, I had decided to pursue a degree in social work, with a concentration in health planning and policy, with the intention of becoming a health planner in one of the federally created Comprehensive Health Planning Agencies.

Between my first and second year of school, a half-time terminal executive directorship became available at the Mental Health Council. It felt like an ideal opportunity to pay for my second year of school. The school I attended didn't generally do field placements for policy students, but they gave me credit for the job as a field placement. So that's actually how I got started, by being hired in July 1975, halftime for one year.

EG: It's an interesting story. The Lake View neighborhood in which the Counseling Center of Lake View is located, you've been a director of the agency here and I think you've "lived" in the agency - in the neighborhood for a long time. Can you talk a bit about the Lake View neighborhood in Chicago?

NG: Well as you said, I've lived in the agency. It feels like that [laughing]. Well, yes, this is obviously a long story, because it goes back to when I moved into the neighborhood in the fall of 1970. I moved into Lake View in 1970 because it was an urban community. It was a marginal community. At that time, it was redlined by the banking industry, and it was even redlined by the insurance industry. I got involved in the community through a variety of community organizing activities. We were doing things like fighting slum landlords, inviting them to meet with community residents and confronting them about their failure to maintain their property, taking them to court if necessary. We worked on problems such as combating gangs; these were not the kind of gangs you came to think of later on, the huge drug rings or anything like that. It was just your more traditional youth gangs. Some of the things I did there were slightly different from what some of the other community leaders would do. Rather than seeing this as a problem of law enforcement and demanding police action, we brought in organizations that did street work with gang youth. We also worked with the Chicago Mural Project and painted a couple wall murals with kids who were involved in these gangs. So I took very much of a community social work type of approach to what was done, along with the Alinsky style of organizing that I was learning. Toward the end of the decade, I was able to purchase a house here, which is really the only way I was able to continue living in the community as it began to gentrify. So it was a very lucky decision.

I have stayed involved through the ' 80 s and '90s and right into the twenty-first century. The ' 80 s were an interesting era. By that time, we had begun to turn the community around. It had overcome an economic hump, and there was beginning to be some investment in the community. Housing prices were beginning to go up. But at the beginning of the ' 80 s, of course, we had the election of Ronald Reagan. The combination of cutbacks in federal funding along with recession, which Reagan used for bringing down the high inflation rate from the Carter era, had an economically chilling effect. And so it was an era where there was actually quite a bit of community ferment, especially in the religious community. A number of other community leaders and I started a group called Lake View Emergency Relief Project (LERP). We created a shelter for the homeless and a new food pantry. The networking went on-we got a grant and hired a social worker to serve the clientele of the several pantries and the shelter. By that time I was well into my job with the Counseling Center of Lake View. LERP was a good way to link the agency with the religious community and other social service agencies. The network of pantry and shelter services was needed by our clientele as well as others in the neighborhood.

In the '90s, we created another new organization called the Lake View Action Coalition (LAC). That's an organization-based community organization. We have over 40 members, mostly religious institutions and social service agencies. We work primarily on affordable housing issues. As the community gentrified, the issue of access to affordable housing for low-income people became greater. Organizing to maintain and create affordable housing fit very well with the needs of our clientele. I'd say that when clients terminate with us, one of the more frequent reasons you might find-and this might be different from some other places-is because of the gentrification process; that is, they've lost their place to live.

I also worked in the '90s and continue to work with the local merchants association, which in some ways may seem really strange to folks, but it's been very helpful in creating a safe, secure, and attractive environment around the agency, and I've always taken the position that people who come into an agency like ours, serving people who are low income, and also with a lot of problems, should have a safe, secure, and attractive environment, no different from what a middle income or upper income individual would expect to have when looking for services.

We also need to look at the issue of violence and how that impacts persons with mental illness. Of course, the stereotype of persons with mental illness is that they are dangerous. But the true picture is more often that they present as inattentive to what is happening around them; weak and perhaps homeless. They are much more frequently the victims of violence. I know that over the history of the agency there have been a number of instances of clients who have been murdered, or assaulted in some fashion. I know of no instance where one of our clients murdered anyone else.

So those are some of the ways in which I've interacted with the community. I've also done a lot of work with our 
elected representatives. Most of our funding comes from the state, just a small amount from the city, the United Way, and foundations. This past year an aldermanic seat became open in our community. We were able to organize a candidates' forum with our staff, put forward a number of our issues and concerns (including affordable housing) and actually secured commitments on six different issues of concern. One of those was that, if any kind of community planning board were created, our sector, i.e. the nonprofit social service sector, would be represented. When a community planning entity was created, our agency was selected, and I have had a leadership role in that group, as well. I've always positioned myself in terms of community activities within the context of being the director of the Counseling Center of Lake View. It's been very productive, I think, for the agency.

EG: We covered a lot of territory-29 years as you look at your role as executive director at Counseling Center of Lake View. What do you think lies ahead for behavioral healthcare, based on your experience? What you have seen so far? What can we expect in the future?

NG: Well, Yogi Berra is the one who is alleged to have said, "Predictions are hard to make, especially when they're about the future." And so, I'm always very reluctant to make any predictions about the future. I think what I do have is a sense of what are some areas where I think it's important for us to move-not just in this agency, but in the field as a whole. Number one is the whole arena of housing. I think that we can no longer just say that housing is somebody else's business. As a field, we have to find a variety of strategies to ensure that people are both housed and provided supportive services. Housing will be a key issue because it ties very much into addressing the incarceration issue. Even the folks in the criminal justice arena are complaining about incarcerating our clientele in the jails and prisons. They feel these are inappropriate people to be in jails and prison; they want them out. They like to deal with criminals. They don't want to be dealing with the folks who are psychotic or whatever. So, there is actually interest in the criminal justice arena to moving people out of the jails and prisons and back into the community. Part of the equation of moving them back into the community has to be the provision of housing.

Another arena is vocational services. I don't know that this is true in every state in the country, but I would say in Illinois, we're very weak when it comes to providing the kind of orientation, services, and support to help people move into some kind of job. Hopefully, we're beyond the era where we look at very simplistic jobs such as packaging incense or things like that, because I think the people whom we serve may be ill, but they're not necessarily unintelligent and they're not necessarily even uneducated. There are folks who have medical degrees in our caseloads. So we don't have to be looking at demeaning types of work. We do have to individualize these services, so that we're allowing each individual to be successful in terms of a career, in terms of a life path. Part of that in a society like this is having a job that pays a living wage. So I think we have to become more proficient in addressing the vocational issue.

The vocational emphasis fits into what is being promoted at the federal level, and to some degree at the state level, and we'll see how long this push really continues-that is, the wellness and recovery approach, or movement, to which I alluded to before. This approach, known in Illinois as psychosocial rehabilitation, is growth and empowerment-oriented, focusing on mainstreaming rather than mere symptom reduction. It sees itself in contrast to a problemoriented and medications focus that you sometimes see. Looking forward, consumer empowerment and a recovery focus are definite themes that will carry into the future.

One of the areas that happens to be a particular interest of mine over many years is the issue of violence and nonviolence. I think that mental health services can have much more to offer in terms of dealing with the impact of violence that, in many cases, is part of the life history of people who have mental health problems. Persons experiencing violence in childhood can be vulnerable to mental illness when they grow up. For a number of years, we have had a focus on the brain. Now we're not going back to naïve types of environmental theories of mental illness in adulthood, but we are understanding much more the degree to which traumatic experiences of various types throughout childhood into adulthood can contribute to mental illness as an adult. So I think we need to understand that connection better. We need to make that more a part of our assessment. When we're working with people, we need to understand better what kind of experiences they have had. We also need to be willing to address and work with people who have exhibited violent behavior. We tend to be afraid of those people-and I'm not saying that they're not some people to be afraid of-because there are some people who are quite dangerous. We don't always do a kind of differential diagnosis and look at what led to the individual's violence and assess the degree to which we need to be "afraid." But violence is a pervasive phenomenon in our society and somehow we as a community mental health field must begin to address that situation in a much more systematic way than we have. We need to begin to have more of a transforming presence, and not only for individuals, but also for the society at large. So these are some of the things that I would hope to see in the future for community mental health.

Edward J. Gumz, PhD, is associate professor, Loyola University Chicago, School of Social Work, Chicago, IL. He is also the book review editor of Families in Society. Correspondence regarding this article may be sent to egumz@luc.edu. 